\title{
Learning Natural Science Materials Of Light Through Cooperative Learning Model Class IV SDN Tiyaran 02
}

\author{
Meti Tri Hayati \\ SDN Tiyaran 02 \\ metisdtiyaran02@gmail.com
}

\section{Article History}

received 3/12/2020

revised $17 / 12 / 2020$

accepted 31/12/2020

\begin{abstract}
To realize the quality of learning and the quality of graduates at SDN Tiyaran 02, especially class IV, it is necessary to use one of the recommended HOTS-oriented learning models in the implementation of the 2013 Curriculum, namely the Cooperative Learning model. Cooperative Learning learning model is a teaching and learning strategy that works on attitudes or helping among others in an organized organization in groups, consisting of two or more people. After implementing integrated thematic learning with the Cooperative Learning model, the authors found that the process and student learning outcomes improved. Better than the previous lesson. When the Cooperative Learning model is applied to other learning materials, it turns out that the process and student learning outcomes are just as good. The writer concludes that this cooperative learning learning practice is successful as a best practice for HOTS learning with the Cooperative Learning model.
\end{abstract}

Keywords: science learning, learning outcomes, cooperative learning

\begin{abstract}
Abstrak
Untuk mewujudkan kualitas pembelajaran dan kualitas lulusan di SDN Tiyaran 02 khususnya kelas IV, perlu menggunakan salah satu model pembelajaran yang berorientasi pada HOTS yang disarankan dalam implementasi Kurikulum 2013 adalah model Pembelajaran Cooperative Learning. Model pembelajaran Cooperative Learning adalah suatu strategi belajar mengajar yang menekankan pada sikap atau perilaku bersama dalam bekerja atau membantu di antara sesama dalam struktur kerjasama yang teratur dalam kelompok, yang terdiri dari dua orang atau lebih. Setelah melaksanakan pembelajaran tematik terpadu dengan model Cooperative Learning, penulis menemukan bahwa proses dan hasil belajar siswa meningkat. Lebih bagus dibandingkan pembelajaran sebelumnya. Ketika model Cooperative Learning ini diterapkan pada materi pembelajaran yang lain ternyata proses dan hasil belajar siswa sama baiknya. Praktik pembelajaran Cooperative Learning yang berhasil baik ini penulis simpulkan sebagai sebuah best practice (praktik baik) pembelajaran berorientasi HOTS dengan model Cooperative Learning.
\end{abstract}

Kata kunci: pembelajaran IPA, hasil belajar, pembelajaran kooperatif

Social, Humanities, and Education Studies (SHEs): Conference Series https://jurnal.uns.ac.id/shes

p-ISSN 2620-9284 e-ISSN 2620-9292 


\section{PENDAHULUAN}

Dalam praktik pembelajaran tematik terpadu yang terintegrasi dalam kurikulum 2013 menuntut dua hal yang mendasar yakni kualitas pembelajaran dan juga kualitas lulusan. Juga arah kebijakan Kementrian Pendidikan dan Kebudayaan pada tahun 2018 telah mengitegrasikan Penguatan Pendidikan Karakter dan pembelajaran berorientasi pada Keterampilan Berpikir Tingkat Tinggi atau Higher Order Thinking Skill (HOTS). Berkaitan dengan hal tersebut SDN Tiyaran 02 tidak terlepas dari berbagai kendala untuk mencapainya. Salah satunya terjebak dalam kegiatan rutinitas yakni pembelajaran yang belum berorientasi pada Ketrampilan Berpikir Tingkat Tinggi.

Berdasarkan evaluasi diri ditemukan berbagai kelemahan dalam pembelajaran yang selama ini telah dilaksanakan. Yakni kualitas lulusan yang semakin jauh dari KKM yang telah ditentukan. Berawal dari tingkat antusias siswa dalam pembelajaran karena pegunaan model pembelajaran yang monoton. Untuk mewujudkan kualitas pembelajaran dan kualitas lulusan di SDN Tiyaran 02 khususnya kelas IV, salah satu model pembelajaran yang berorientasi pada HOTS dan disarankan dalam implementasi Kurikulum 2013 adalah model Pembelajaran Cooperative Learning.

Pembelajaran kooperatif adalah model pembelajaran yang berfokus pada penggunaan kelompok kecil siswa untuk bekerja sama dalam memaksimalkan kondisi belajar untuk mencapai tujuan belajar (Sugiyanto, 2010: 37). Model pembelajaran Cooperative Learning adalah suatu strategi belajar mengajar yang menekankan pada sikap atau perilaku bersama dalam bekerja atau membantu di antara sesama dalam struktur kerjasama yang teratur dalam kelompok, yang terdiri dari dua orang atau lebih. Setelah melaksanakan pembelajaran tematik terpadu dengan model Cooperative Learning, penulis menemukan bahwa proses dan hasil belajar siswa meningkat. Lebih bagus dibandingkan pembelajaran sebelumnya. Ketika model Cooperative Learning ini diterapkan pada materi pembelajaran yang lain ternyata proses dan hasil belajar siswa sama baiknya.

Slavin dalam Isjoni (2009: 15) pembelajaran kooperatif adalah suatu model pembelajaran dimana siswa belajar dan bekerja dalam kelompok- kelompok kecil secara kolaboratif yang anggotanya 5 orang dengan struktur kelompok heterogen. Sedangkan menurut Sunal dan Hans dalam Isjoni (2009:15) mengemukakan bahwa pembelajaran kooperatif merupakan suatu cara pendekatan atau serangkaian strategi yang khusus dirancang untuk memberi dorongan kepada siswa agar bekerja sama selama proses pembelajaran. Selanjutnya Stahl dalam Isjoni (2009: 15) menyatakan pembelajaran kooperatif dapat meningkatkan belajar siswa lebih baik dan meningkatkan sikap saling tolong-menolong dalam perilaku sosial.

Pembelajaran kooperatif adalah model pembelajaran yang berfokus pada penggunaan kelompok kecil siswa untuk bekerja sama dalam memaksimalkan kondisi belajar untuk mencapai tujuan belajar (Sugiyanto, 2010: 37). Anita Lie (2007: 29) mengungkapkan bahwa model pembelajaran cooperative learning tidak sama dengan sekedar belajar dalam kelompok. Ada lima unsur dasar pembelajaran cooperative learning yang membedakannya dengan pembagian kelompok yang dilakukan asalasalan. Pelaksanaan model pembelajaran kooperatif dengan benar akan menunjukkan pendidik mengelola kelas lebih efektif.

Johnson (Anita Lie,2007: 30) mengemukakan dalam model pembelajaran kooperatif ada lima unsur yaitu: saling ketergantungan positif, tanggung jawab perseorangan, tatap muka, komunikasi antar anggota, dan evaluasi proses kelompok.

Pembelajaran kooperatif (Cooperative learning) adalah model pembelajaran yang menekankan pada saling ketergantungan positif antar individu siswa, adanya tanggung jawab perseorangan, tatap muka, komunikasi intensif antar siswa, dan evaluasi proses kelompok (Arif Rohman, 2009: 186).

Cooperative learning menurut Slavin (2005: 4-8) merujuk pada berbagai macam model pembelajaran di mana para siswa bekerja sama dalam kelompok-kelompok 
kecil yang terdiri dari berbagai tingkat prestasi, jenis kelamin, dan latar belakang etnik yang berbeda untuk saling membantu satu sama lain dalam mempelajari materi pelajaran. Dalam kelas kooperatif, para siswa diharapkan dapat saling membantu, saling mendiskusikan, dan berargumentasi untuk mengasah pengetahuan yang mereka kuasai saat itu dan menutup kesenjangan dalam pemahaman masing-masing. Cooperative learning lebih dari sekedar belajar kelompok karena dalam model pembelajaran ini harus ada struktur dorongan dan tugas yang bersifat kooperatif sehingga memungkinkan terjadi interaksi secara terbuka dan hubungan-hubungan yang bersifat interdependensi efektif antara anggota kelompok.

Agus Suprijono (2009: 54) mengemukakan bahwa pembelajaran kooperatif adalah konsep yang lebih luas meliputi semua jenis kerja kelompok termasuk bentukbentuk yang lebih dipimpin oleh guru atau diarahkan oleh guru. Secara umum pembelajaran kooperatif dianggap lebih diarahkan oleh guru, di mana guru menetapkan tugas dan pertanyaan- pertanyaan serta menyediakan bahan-bahan dan informasi yang dirancang untuk membantu siswa menyelesaikan masalah yang dimaksudkan. Guru biasanya menetapkan bentuk ujian tertentu pada akhir tugas.

Anita Lie (Agus Suprijono, 2009: 56) menguraikan model pembelajaran kooperatif ini didasarkan pada falsafah homo homini socius. Berlawanan dengan teori Darwin, filsafat ini menekankan bahwa manusia adalah makhluk sosial. Dialog interaktif (interaksi sosial) adalah kunci seseorang dapat menempatkan dirinya di lingkungan sekitar.

Dari beberapa definisi yang dikemukakan oleh para ahli di atas, maka dapat ditarik kesimpulan bahwa pembelajaran kooperatif adalah model pembelajaran yang menempatkan siswa dalam kelompok-kelompok kecil yang anggotanya bersifat heterogen, terdiri dari siswa dengan prestasi tinggi, sedang, dan rendah, perempuan dan laki-laki dengan latar belakang etnik yang berbeda untuk saling membantu dan bekerja sama mempelajari materi pelajaran agar belajar semua anggota maksimal.

\section{METODE}

Penelitian ini berupa Laporan Best Practice. Tujuan penulisan Laporan Best Practice ini adalah untuk mendeskripsikan Laporan Best Practice dalam penerapan Pembelajaran Cooperative Learning yang terintegrasi dengan Penguatan Pendidikan Karakter dan berorientasi pada Keterampilan Berpikir Tingkat Tinggi atau Higher Order Thinking Skill (HOTS). Sasaran pelaksanaan Best Practice ini adalah siswa kelas IV SDN Tiyaran 02 semester Gasal tahun ajaran 2019/2020, sebanyak 8 siswa.

\section{HASIL DAN PEMBAHASAN}

Tujuan penulisan Laporan Best Practice ini adalah untuk mendeskripsikan Laporan Best Practice dalam penerapan Pembelajaran Cooperative Learning yang terintegrasi dengan Penguatan Pendidikan Karakter dan berorientasi pada Keterampilan Berpikir Tingkat Tinggi atau Higher Order Thinking Skill (HOTS).

Sasaran pelaksanaan Best Practice ini adalah siswa kelas IV SDN Tiyaran 02 semester Gasal tahun ajaran 2019/2020, sebanyak 8 siswa.

Bahan yang digunakan dalam Best Practice ini adalah materi kelas IV Tema Pahlawanku Sub Tema Perjuangan Para Pahlawan, Pembelajaran ke - 1 dengan Materi Pokok Sifat-sifat cahaya muatan pealajaran IPA dan Bahasa Indonesia. Dengan Kompetensi Dasar sebagai berikut : 
Muatan Bahasa Indonesia

4.7 Menyajikan laporan hasil percobaan tentang sifat-sifat
cahaya
Kompetensi Pengetahuan
3.7 Menggali pengetahuan baru yang didapat dari teks
nonfiksi
Kompetensi Keterampilan
4.7 Menyampaikan pengetahuan baru dari teks nonfiksi
ke dalam tulisan dengan bahasa sendiri

Cara dalam pelaksanaan Best Practice ini adalah penerapan hasil Program Pengembangan Keprofesian Berkelanjutan (PKB) Melalui Peningkatan Kompetensi Pembelajaran (PKP) Berbasis Zonasi di kecamatan Bulu.

Dengan tahapan - tahapan yang telah dilakukan penulis sebagai berikut :

1. Pemilihan Kompetensi Dasar dan Analsis Kompetensi Dasar

a. Pemilihan Kompetensi Dasar

Dengan merujuk Buku Unit Pembelajaran sifat-sifat cahaya yang dikembangkan berdasar kompetensi dasar kelas IV. Kompetensi dasar yang dikembangkan yakni KD IPA Kompetensi Pengetahuan 3.7 Menerapkan sifat-sifat cahaya dan keterkaitannya dengan indera penglihatan, Kompetensi Keterampilan 4.7 Menyajikan laporan hasil percobaan tentang sifat-sifat cahaya dari pemetaan KD kelas IV berada pada Tema 5 Kepahlawanan Sub Tema Perjuangan Para Pahlawan yang terintregasi dengan KD Bahasa Indonesia Kompetensi Pengetahuan 3.7 Menggali pengetahuan baru yang didapat dari teks nonfiksi dan Kompetensi Keterampilan 4.7 Menyampaikan pengetahuan baru dari teks nonfiksi ke dalam tulisan dengan bahasa sendiri. Berikut Pemetaan KD Kelas IV Tema 5.

Tabel 1. Pemetaan Kompetensi Dasar Kelas IV Tema 5

\begin{tabular}{|c|c|c|c|c|c|c|c|c|c|c|c|c|c|c|c|c|c|c|c|c|c|}
\hline \multirow{3}{*}{$\begin{array}{l}\text { MUATAN } \\
\text { PELAJARAN }\end{array}$} & \multirow{3}{*}{\multicolumn{2}{|c|}{ KOMPETENSI DASAR }} & \multicolumn{18}{|c|}{ TEMA 5} & \\
\hline & & & \multicolumn{6}{|c|}{ ST 1} & \multicolumn{6}{|c|}{ ST 2} & \multicolumn{6}{|c|}{ ST 3} & \\
\hline & & & PEI & $\mathrm{PBz}$ & $\mathrm{PE}$ & PEA & PQS & PE6 & PE1 & PB2 & PE3 & 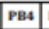 & PES & PE6 & 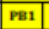 & PEZ & 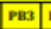 & 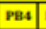 & 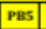 & PB6 & \\
\hline & & & & & & & & & & & & & & & & & & & & & \\
\hline PPKN & 1.3 & $\begin{array}{l}\text { Mensyukuri keberagaman umat beragama di masyarakat dalam kontekef } \\
\text { Bhinneka Tungsal lla }\end{array}$ & & 1.3 & & 13 & & 13 & & 1.3 & & 1.3 & & 13 & & 1.3 & & 13 & & 13 & 9 \\
\hline PPKN & 23 & $\begin{array}{l}\text { Bersikap toleran dalam keberagaman umat beragama di masyarakat } \\
\text { dalam koteks Bhinneka Tungsal lla }\end{array}$ & & 2.3 & & 23 & & 23 & & 2.3 & & 23 & & 23 & & 23 & & 23 & & 23 & 9 \\
\hline PPKN & 3.1 & $\begin{array}{l}\text { Mengasosiasikan makna hubungan simbol dengan sila-sila Pancasilata } \\
\text { dalam kehidupan sehari-hari }\end{array}$ & & 3.1 & & 3.1 & & 3.1 & & 3.1 & & \begin{tabular}{|l|}
3.1 \\
\end{tabular} & & 3.1 & & 3.1 & & 3.1 & & 3.1 & 9 \\
\hline PPKN & 4.1 & $\begin{array}{l}\text { Menceritalan makna hubungan simbol dengan sila-sila Pancassila sebagai } \\
\text { satu kesatuan dalam kehidupan sehari-hari }\end{array}$ & & 4.1 & & 4.1 & & 4.1 & & 4.1 & & 4.1 & & 4.1 & & 4.1 & & 4.1 & & 4.1 & 9 \\
\hline B. INDO & 37 & Menggali pengetahuan baru yang terdapat pada teks nonfikss & 37 & & 3.7 & 3.7 & & & & & & & & 37 & & & & & & 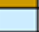 & 4 \\
\hline B. INDO & 3.8 & $\begin{array}{l}\text { Membandingkan bal yang sudah diketahui dengan yang baru diketahui } \\
\text { dari teks nonfikss }\end{array}$ & & & & & & 3.8 & 38 & & 3.8 & \begin{tabular}{|l|}
3.8 \\
\end{tabular} & & & \begin{tabular}{|l|}
3.8 \\
\end{tabular} & & 3.8 & 3.8 & & 3.8 & 8 \\
\hline B. INDO & 4.7 & $\begin{array}{l}\text { Menyampoilan pengetahuan baru dari teks nonfiksi ke dalam tulisan } \\
\text { dengan bahasa sendiri }\end{array}$ & 4.7 & & 4.7 & 4.7 & & 4.7 & & & & & & 4.7 & & & & & & & 5 \\
\hline B. INDO & 4.8 & $\begin{array}{l}\text { Menyampailan hasil membandingkan pengetahuan lama dengan } \\
\text { pengetahuan baru secara tertulis dengan bahase sendiri }\end{array}$ & & & & & & & 4.8 & & 4.8 & 4.8 & & & 4.8 & & 4.8 & 4.8 & & 4.8 & 7 \\
\hline IPA & 37 & Menerapkan sifat-sifat cahaya dan keterkaitannya dengan indera & 37 & & 3.7 & & & & 3.7 & & 3.7 & & & & 3.7 & & 3.7 & & & & 6 \\
\hline IPA & 4.7 & $\begin{array}{l}\text { Menyajikan Laporan hasil pengamatan dan/atau percobsan yang } \\
\text { memanfaatkan sifat-sifat calhaya }\end{array}$ & 4.7 & & 4.7 & & & & 4.7 & & 4.7 & & & & 4.7 & & 4.7 & & & & 6 \\
\hline IPS & 3.4 & $\begin{array}{l}\text { Mengidentifikasi kerajaann Hindu, Buddha dan Islam sertas } \\
\text { pengaruhnya pada kehidupan masyarakat masa kini di } \\
\text { lingkungan daerah setempat }\end{array}$ & 34 & & & & 3.4 & & 3.4 & & & & 3.4 & & $|3.4|$ & & & & 3.4 & & 6 \\
\hline IPS & 4.4 & Menyajikan hasil identifikasi kerajaan Hindu, Buddha dan & 4.4 & & & & 4.4 & & 4.4 & & & & 4.4 & & 4.4 & & & & 4.4 & & 6 \\
\hline SBdP & 3.2 & Mengetahui tanda tempo dan tinggi rendah nada & & 3.2 & & & 32 & & & 3.2 & & & 3.2 & & & 32 & & & 3.2 & & 6 \\
\hline SBdP & 4.2 & Menampillkan Lagu dengan memperhatikan tempo dan tinggi rendah & & 4.2 & & & 42 & & & 4.2 & & & 4.2 & & & 4.2 & & & 4.2 & & 6 \\
\hline & & & 6 & 8 & 6 & 8 & 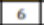 & 8 & 6 & 8 & 6 & 8 & 6 & 8 & 6 & 8 & 6 & 8 & \begin{tabular}{l|l|}
6 & \\
\end{tabular} & 8 & 96 \\
\hline
\end{tabular}

b. Analısıs Kompetensı vasar

Dalam analisis KD sesuai dengan tututan Permendikbud Nomor 37 Tahun 2018 tetang Kompetensi Dasar yang menjadi sasaran minimal yang akan dicapai dan menentukan target yang akan dicapai sesuai dengan Kompetensi Dasar dengan cara memisahkan target kompetensi dengan materi yang terdapat pada KD sesuai format di bawah ini: 
Tabel 2. Format Pasangan KD dengan Target Kompetensi Dasar

\begin{tabular}{|c|c|c|}
\hline No & Kompetensi Dasar & Target Kompetensi \\
\hline & \multicolumn{2}{|l|}{ KD Pengetahuan } \\
\hline 1. & $\begin{array}{l}3.7 \text { Menerapkan sifat- } \\
\text { sifat cahaya dan } \\
\text { keterkaitannya dengan } \\
\text { indera penglihatan }\end{array}$ & $\begin{array}{l}\text { 3.7.1 Menjelaskan sifat-sifat cahaya. } \\
\text { 3.7.2 Menyelidiki sifat-sifat cahaya } \\
\text { 3.7.3 Menyimpulkan keterkaitan sifat-sifat cahaya } \\
\text { dengan indera penglihatan }\end{array}$ \\
\hline & KD Ketrampilan & \\
\hline 2. & $\begin{array}{l}\text { 4.7 Menyajikan laporan } \\
\text { hasil percobaan } \\
\text { tentang sifat-sifat } \\
\text { cahaya }\end{array}$ & $\begin{array}{l}\text { 4.7.1 Menyajikan laporan hasil percobaan tentang } \\
\text { sifat-sifat cahaya }\end{array}$ \\
\hline
\end{tabular}

Untuk menganalisis KD kita proyeksikan pada sumbu simetri berikut :

Tabel 3. Analisis KD 3.1 Menganalisis Sifat-Sifat Cahaya

\begin{tabular}{|c|c|c|c|c|c|c|c|}
\hline \multirow{6}{*}{ 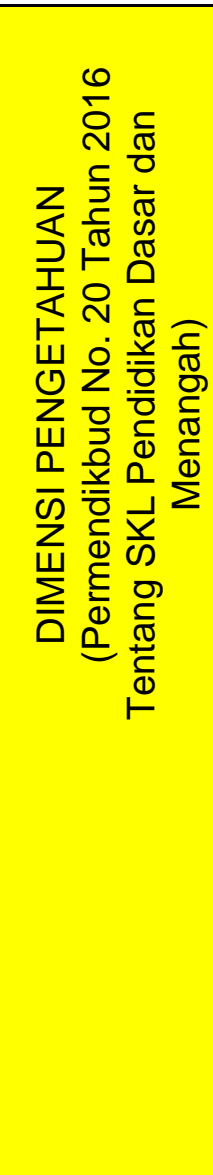 } & $\begin{array}{c}\text { META } \\
\text { KOGNI } \\
\text { TIF }\end{array}$ & & & & & & \\
\hline & $\begin{array}{c}\text { PROS } \\
\text { EDUR } \\
\text { AL }\end{array}$ & & & & $\begin{array}{c}\text { Menya } \\
\text { jikan } \\
\text { lapora } \\
n\end{array}$ & & \\
\hline & $\begin{array}{c}\text { KONS } \\
\text { EPTUA } \\
L\end{array}$ & & & & $\begin{array}{c}\text { Mener } \\
\text { apkan } \\
\text { sifat } \\
\text { cahay } \\
\text { a }\end{array}$ & & \\
\hline & $\begin{array}{l}\text { FAKTU } \\
\text { AL }\end{array}$ & & & & $\begin{array}{l}\text { Mener } \\
\text { apkan } \\
\text { keterk } \\
\text { aitan }\end{array}$ & & \\
\hline & & $\begin{array}{c}\text { C1 } \\
\text { MEN } \\
\text { GING } \\
\text { AT }\end{array}$ & $\begin{array}{c}\text { C2 } \\
\text { MEMA } \\
\text { HAMI }\end{array}$ & $\begin{array}{c}\text { C3 } \\
\text { MENGAPL } \\
\text { IKASIKAN }\end{array}$ & $\begin{array}{c}\text { C4 } \\
\text { MENG } \\
\text { ANALI } \\
\text { SIS }\end{array}$ & $\begin{array}{c}\text { C5 } \\
\text { MEN } \\
\text { GEV } \\
\text { ALU } \\
\text { ASI }\end{array}$ & $\begin{array}{c}\text { C6 } \\
\text { MENCI } \\
\text { PTA }\end{array}$ \\
\hline & & \multicolumn{6}{|c|}{$\begin{array}{c}\text { DIMENSI PROSES BERFIKIR } \\
\text { Ranah Kognitif }(\mathrm{C} 1-\mathrm{C} 6) \text { Taksonomi Bloom }\end{array}$} \\
\hline
\end{tabular}

2. Perumusan Indikator Pencapaian Kompetensi

Perumusan indikator pencapaian kompetensi dapat dilakukan dengan mengikuti langkah sebagai berikut:

a. Perhatikan dimensi proses kognitif dan dimensi pengetahuan yang menjadi target yang harus dicapai peserta didik; 
b. Tentukan KD yang akan diturunkan menjadi IPK;

c. Menggunakan kata kerja operasional yang sesuai untuk perumusan IPK agar konsep materi dapat tersampaikan secara efektif. Gradasi IPK diidentifikasi dari Lower Order Thinking Skills (LOTS) menuju Higher Order Thinking Skills (HOTS);

d. Merumuskan IPK pendukung dan IPK kunci, sedangkan IPK pengayaan dirumuskan apabila kompetensi minimal KD sudah dipenuhi oleh peserta didik.

Dari langkah - langkah tersebut dari KD 3.1 dapat ditentukan Indikator Pencapaian Kompetensi sebagai berikut :

Tabel 4. Indikator Pencapaian Kompetensi 3.7

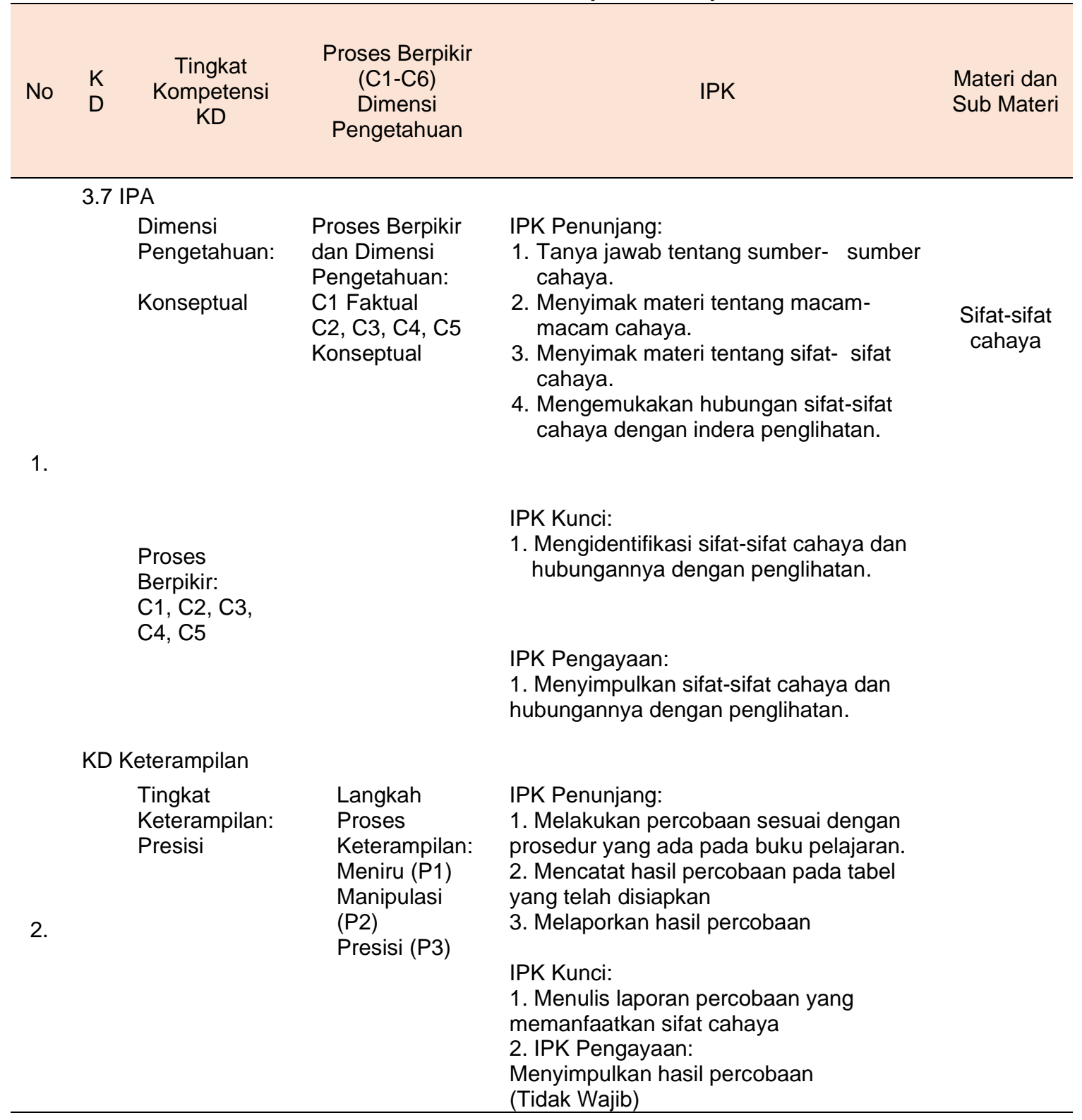

3. Penentuan Model Pembelajaran berikut :

Dalam menentukan model pembelajaran dengan memperhatikan hal-hal sebagai

a. Memahami sintaks tiap model pembelajaran;

b. Menganalisis konten/materi pembelajaran; 
c. Memahami konteks peserta didik;

d. Jika peseta didik belum siap, perlu dibangun jembatan penghubung antara proses LOTS menuju HOTS yaitu membangun skema pengetahuan awal dengan pengetahuan baru.

e. Mempersiapkan sebuah situasi nyata yang dapat menstimulasi proses berpikir tingkat tinggi dengan menciptakan dilema, kebingungan, tantangan, dan ambiguitas dari permasalahan yang direncanakan akan dihadapi peserta didik

f. Menentukan keterampilan yang akan digunakan untuk menghadapai situasi nyata tersebut;

g. Mempertimbangkan alokasi waktu pembelajaran;

h. Menentukan luaran (output) yang akan dihasilkan; dan

i. Menganalisis situasi, keterampilan, dan luaran dengan sintak model pembelajaran untuk menentukan model yang relevan.

Setelah mempertimbangkan hal-hal tersebut diatas dipilihlah model pembelajaran Cooperative Learning.

4. Menyusun Rencana Pembelajaran

Pengembangan rencana pembelajaran dengan memperhatikan sintak model pembelajaran Cooperative Learning. Berikut ini merupakan rencana pembelajaran yang dipersiapkan.

Tabel 5. Rencana Pembelajaran dengan model Cooperative Learning.

\begin{tabular}{|c|c|c|c|}
\hline $\begin{array}{l}\text { Sintak Model } \\
\text { Pembelajaran }\end{array}$ & & Guru & Siswa \\
\hline $\begin{array}{l}\text { Fase 1: } \\
\text { Present goal } \\
\text { and set } \\
\text { Menyampaikan } \\
\text { tujuan dan } \\
\text { mempersiapkan } \\
\text { peserta didik }\end{array}$ & & $\begin{array}{l}\text { Menjelaskan tujuan } \\
\text { pembelajaran dan } \\
\text { mempersiapkan peserta } \\
\text { didik siap belajar dengan } \\
\text { mengajukan pertanyaan, } \\
\text { anjuran membaca buku, } \\
\text { dan aktivitas belajar } \\
\text { lainnya yang mengarah } \\
\text { pada persiapan } \\
\text { pemecahan masalah. }\end{array}$ & $\begin{array}{l}\text { 1. Siswa diingatkan untuk selalu } \\
\text { mengutamakan sikap disiplin } \\
\text { setiap saat dan manfaatnya } \\
\text { bagi tercapainya cita-cita. } \\
\text { 2. Siswa menunjukkan tugas yang } \\
\text { diberikan sebelumnya, } \\
\text { kemudian membahasnya } \\
\text { sebentar. } \\
\text { 3. Siswa memperhatikan tujuan } \\
\text { pembelajaran hari ini yang } \\
\text { disampaikan oleh quru. }\end{array}$ \\
\hline $\begin{array}{l}\text { Fase 2: } \\
\text { Present } \\
\text { information } \\
\text { Menyajikan } \\
\text { informasi }\end{array}$ & & $\begin{array}{l}\text { Guru mempresentasikan } \\
\text { informasi kepada } \\
\text { peserta didik secara } \\
\text { verbal dengan memberi } \\
\text { kesempatan kepada } \\
\text { peserta didik untuk } \\
\text { mengidentifikasi } \\
\text { sebanyak mungkin } \\
\text { agenda-agenda masalah } \\
\text { yang relevan dengan } \\
\text { bahan pelajaran, } \\
\text { kemudian salah satunya } \\
\text { dipilih dan dirumuskan } \\
\text { dalam bentuk hipotesis } \\
\text { (jawaban sementara } \\
\text { atas pertanyaan } \\
\text { masalah). }\end{array}$ & $\begin{array}{l}\text { 1. Siswa diingatkan kesepakatan } \\
\text { yang telah disusun bersama } \\
\text { tentang keamanan dan } \\
\text { kenyamanan dalam melakukan } \\
\text { percobaan } \\
\text { Kesepakatan Kegiatan Percobaan } \\
\text { IPA } \\
\text { a. Setiap anggota aktif membaca } \\
\text { langkah kegiatan dengan } \\
\text { seksama } \\
\text { b. Melakukan percobaan dengan } \\
\text { sungguh-sungguh } \\
\text { c. Tunjuk tangan apabila ingin } \\
\text { bertanya } \\
\text { d. Memperlakukan barang dengan } \\
\text { e. Mati-hati } \\
\text { e. Merapikan perlengkapan }\end{array}$ \\
\hline
\end{tabular}




\section{Fase 3: \\ organize student into learning team Mengorganisasi peserta didik kedalam tim-tim belajar}

Fase 4 : assist team work and study

Membantu kerja tim dan belajar

Fase 5 : test on materials Mengevaluasi

setelah kegiatan selesai

Memberikan penjelasan kepada peserta didik tentang tata cara membentuk tim belajar dan membantu kelompok melakukan transisi yang efisien Ketika eksplorasi berlangsung guru juga memberi kesempatan kepada para peserta didik untuk mengumpulkan informasi yang relevan sebanyak-banyaknya untuk membuktikan benar atau tidaknya hipotesis.

> Guru membantu tim-tim belajar selama peserta didik mengerjakan tugasnya dan melakukan bimbingan pada saat peserta didik melakukan pengolahan data.

> Guru melakukan pengamatan untuk menilai sikap dan keterampilan peserta didik

$>$ Menguji pengetahuan peserta didik mengenai berbagai materi pembelajaran atau kelompok-kelompok mempresentasikan hasil kerjanya dan Verifikasi bertujuan agar proses belajar akan berjalan dengan baik dan kreatif jika guru memberikan kesempatan kepada peserta didik untuk menemukan suatu konsep, teori, aturan atau pemahaman melalui contoh-contoh yang ia jumpai dalam
1. Siswa membentuk kelompok.

1. Siswa diminta untuk mengajukan pertanyaan dari materi yang belum dipahami

2. Siswa menanyakan materi sifat-sifat cahaya yang belum di pahami

1. Siswa diberikan soal untuk dikerjakan sehingga guru mengetahui kemampuan peserta didik. 


\begin{tabular}{|c|c|c|c|}
\hline & $>$ & $\begin{array}{l}\text { kehidupannya. } \\
\text { Guru menyampaikan } \\
\text { beberapa pertanyaan } \\
\text { benar atau tidaknya } \\
\text { hipotesis. }\end{array}$ & \\
\hline $\begin{array}{l}\text { Fase } 6 \text { : } \\
\text { provide } \\
\text { recognition } \\
\text { Memberikan } \\
\text { pengakuan dan } \\
\text { penghargaan }\end{array}$ & 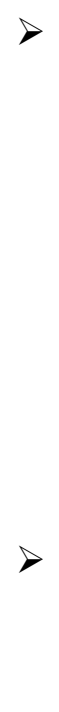 & $\begin{array}{l}\text { Mempersiapkan cara } \\
\text { untuk mengakui usaha } \\
\text { dan prestasi individu } \\
\text { maupun kelompok dan } \\
\text { Proses menarik sebuah } \\
\text { kesimpulan yang dapat } \\
\text { dijadikan prinsip umum } \\
\text { dan berlaku untuk } \\
\text { semua kejadian atau } \\
\text { masalah yang sama, } \\
\text { dengan memperhatikan } \\
\text { hasil verifikasi. } \\
\text { Mendampingi dan } \\
\text { menfasilitasi peserta } \\
\text { didik dalam menarik } \\
\text { kesimpulan. }\end{array}$ & $\begin{array}{l}\text { 1. Siswa yang hasilnya bagus } \\
\text { diberikan penghargaan. }\end{array}$ \\
\hline
\end{tabular}

5. Penyusunan Perangkat Pembelajaran

Dalam penyusunan pembelajaran dengan model Cooperative learning mengimplementasikan Kurikulum 13 menurut Permendikbud Nomor 22 tahun 2016 tentang Standar Proses diharapkan membentuk perilaku saintifik, sosial serta rasa keingintahun.

Perangkat pembelajaran tertuang dalam RPP lengkap dengan Bahan Ajar, LKPD, dan Instrumen Penilaian.

Dalam penyusunannya dilaksanakan dalam tiga tahap yaitu:

a. Penyusunan RPP berdasarkan hasil tahap $1-4$ diatas

b. Mereview RPP bersama Kepala Sekolah

c. Melakukan perbaikan sebagai tindak lanjut review RPP

Hasil akhir penyusunan RPP terlampir.

Media dan alat yang digunakan dalam kegiatan ini merupakan alat peraga dan media dalam pembelajaran dengan model Cooperative learning sebagai berikut :

a. Media pembelajaran

1. Lembar Kerja Peserta Didik (LKPD)

b. Alat Pembelajaran

1. LCD

2. Layar

3. Laptop

4. Perlengkapan untuk percobaan IPA, setiap kelompok membutuhkan Kardus bekas

5. Cermin datar 2 buah

6. Lem/selotip

7. Busur derajat

8. Gunting

9. Kertas biasa atau kertas koran maupun kertas pembungkus kado.

10. 1 Senter

11. 1 Pensil

12. 1 Gelas 
13. 3 Karton tebal

14. 1 Lilin

Waktu dan tempat kegiatan, pelaksanaan kegiatan ini dilaksanakan dari tanggal 26 Nopember - 12 Desember 2019, bertempat di SDN Tiyaran 02.

Hasil dari Pembelajaran dengan Model Cooperative Lerning dapat diuraikan sebagai berikut:

1, Meningkatkan minat dan motivasi peserta didik dalam mengikuti proses pembelajaran yang dapat dilihat dari antusias, keaktifan dan peran serta pererta didik dalam pembelajaran.

2. Meningkatkan ketrampilan dalam berkomunikasi (communication) peserta didik, yang dapat dilihat dari aktivitas diskusi Tanya jawab dan juga presentasi hasil diskusi.

3. Meningkatkan ketrampilan kerjasama (collaborative) peserta didik, dapat diamati dari proses penyelesaian tugas kelompok dalam menyelesaiakan LKPD.

4. Meningkatkan ketrampilan berpikir kritis dan pemecahan masalah (critical thinking and problem solving) yang dapat dilihat dari keberhasilan dalam mengatasi masalah dalam penyelesaian LKPD.

Sehingga kualitas proses pembelajaran dan kualitas lulusan dengan membentuk perilaku saintifik, sosial, serta rasa keingintahuan peserta didik dapat ditingkatkan.

Dalam pelaksanaan kegiatan ini timbul beberapa masalah dalam perencanaan pembelajaran hingga evaluasi akhir pembelajaran. Terkait dalam perencanaan pembelajaran, pendalaman materi dari tenaga pendidik masih membutuhkan banyak referensi lagi untuk memperluas cakupan materi yang dikuasai. Selama ini buku guru dan buku siswa yang dijadikan acuan masih perlu ditambah lagi dari sumber yang lain. Kemudian penyusunan perangkat pembelajaran yang di butuhkan masih terdapat banyak kelemahan dikarenakan kemampuan tenaga pendidik yang perlu ditingkatkan.

Serta minat dan motivasi belajar peserta didik yang belum maksimal membutuhkan banyak bimbingan dan arahan dari tenaga pendidik yang lebih. Karena penggunaan model pembelajaran sebelumnya yang terkesan pembelajaran terpusat pada tenaga pendidik.

Dalam mengatasi masalah yang dihadapi berkaitan dengan masih minimnya referensi materi pembelajaran dari tenaga pendidik. Dapat diselesaikan dengan mengumpulkan sumber-sumber belajar yang lain dari buku-buku pelajaran yang lain, atau artikel artikel yang sesuai dengan materi.

Kemudian kemampuan tenaga pendidik dalam menyusun perangkat pembelajaran dapat ditingkatkan dengan bertukar wawasan kepada teman sejawat, atau berkonsultasi dengan Kepala Sekolah selaku pimpinan dalam unit kerja.

Perubahan model pembelajaran yang terpusat pada siswa akan semakin meningkatkan minat dan motivasi peserta didik dalam mengembangkan Higher order thinking skill . namun kelemahan pada masa transisi yakni kemampuan communication yang masih lemah. Membuat siswa sedikit kebingungan dalam menangkap dan menyampaikan informasi, sehingga penyelesaiannya dengan menggunakan kalimat yang efektif dalam memberikan bimbingan dan arahan sehingga lebih efisien dan mudah difahami oleh peserta didik.

\section{SIMPULAN}

Berdasarkan latar belakang masalah, tujuan, pelaksanaan hingga hasil yang telah dideskripsikan pada BAB sebelumnya dapat ditarik kesimpulan sebagai berikut :

1) Dalam pembelajaran IPA materi Sifat-sifat cahaya dengan model Cooperative learning terjadi proses intuitif pada peserta didik yang akhinya sampai pada kesimpulan. 
2) Antusias dan motivasi belajar peserta didik yang meningkat dalam setiap tahap pembelajaran.

3) Peserta didik dapat mengembangkan kemampuan berkomunikasi (communication skill) ,kemampuan berkerjasama (collaboration), kemampuan berpikir kritis dan menyelesaikan masalah (critical thinking and problem solving).

4) Sehingga pembelajaran dengan model Cooperative learning dapat dijadikan laporan Best Practice Pembelajaran dengan berorientasi Higher Order Thinking Skill (HOTS).

Mengacu pada hasil Best Practice Pembelajaran IPA materi Sifat-Sifat Cahaya dengan model Cooperative learning berikut disampaikan rekomendasi yang relevan.

1. Guru seharusnya mempersiapkan perangkat pembelajaran dengan maksimal sehingga meminimalkan kendala dalam pembelajaran, dan dapat mencapai tujuan pembelajaran dengan baik. Dan dapat menggunakan model Cooperative learning sebagai salah satu alternatif model pembelajaran tematik IPA, untuk meningkatkan kualitas proses pembelajaran dan kualitas lulusan.

2. Peserta didik selalu mengembangkan kemampuan berpikir tingkat tinggi dalam belajar, tidak terbatas pada hafalan teori. Kemampuan belajar dengan cara ini akan membantu peserta didik menguasai materi secara lebih mendalam dan lebih tahan lama (tidak mudah lupa).

3. Sekolah, terutama kepala sekolah dapat mendorong guru lain untuk ikut melaksanakan pembelajaran berorientasi HOTS. Dukungan positif sekolah, seperti penyediaan sarana dan prasarana yang memadai dan kesempatan bagi penulis untuk mendesiminasikan best practice ini akan menambah wawasan guru lain tentang pembelajaran Higher Order Thinking Skill (HOTS).

\section{DAFTAR PUSTAKA}

Angi St Anggari, Afriki dkk. 2017. Pahlawanku: Buku Siswa. Jakarta: Kemdikbud.

Anita Lie, 2007. Cooperative Learning. Jakarta: Gramedia

Ariana, Yoki dkk. 2019. Pembelajaran Berorientasi pada Ketrampilan Berpikir Tingkat Tinggi : Buku Pegangan. Jakarta : Direktorat Jendral Guru dan Tenaga Kependidikan, Kementrian Pendidikan dan Kebudayaan.

Arif Rohman. (2009). Memahami Pendidikan dan Ilmu Pendidikan. Yogyakarta: LaksBang Mediatama.

Asma, Nur. (2006). Model Pembelajaran Kooperatif. Jakarta: Departemen Pendidikan Nasional Direktorat Jendral Pendidikan Tinggi.

Dimyati dan Mujiono. 2006. Belajar dan Pembelajaran(Jakarta: Rineka Cipta)

Huda, Miftahul. 2011. Cooperative Learning. (Yogyakarta: Pustaka Belajar)

Isjoni. 2009. Pembelajaran Kooperatif. Yogyakarta: Pustaka Pelajar

Kemendikbud. 2018. Permendikbud Nomor 37 Tahun 2018 Tentang KI dan KD Kurikulum 2013 Jenjang SD/MI SMP/MTS SMA/MA. Jakarta: Kemendikbud

Kemendikbud. 2016. Permendikbud Nomor 22 tahun 2016 tentang Standar Proses. Jakarta : Kemendikbud.

Luluk Ayuning Dyah P., M.Si.2019. Unit Pembelajaran Program Peningkatan Keprofesian Berkelanjutan Melalui Peningkatan Kompetensi Pembelajaran Berbasis Zonasi Mata Pelajaran IImu Pengetahuan Alam SD Cahaya: Buku Pegangan. Jakarta: Kemendikbud.

Roestiyah NK., Strategi Belajar Mengajar, Jakarta: Rineka Cipta, 2001

Sugiyanto. (2010). Model-model Pembelajaran Inovatif. Surakarta: Yuma Pustaka.

Suprijono, Agus. 2009. Cooperative Learning(Yogyakarta : Pustaka Pelajar)

Zaini, Hisyam, Bermawy Munthe, dan Sekar Ayu Aryani. 2008. Strategi Pembelajaran Aktif. Yogyakarta: CTSD IAIN Sunan Kalijaga. 